\title{
Study of Catalytic Hydrogenation and Methanol Addition to $\alpha$-Methylene- $\gamma$-Lactone of Eremanthine Derivatives
}

\author{
José C. F. Alves \\ Departamento de Química, Instituto de Ciências Exatas, Universidade Federal Rural do Rio de Janeiro, \\ 23890-970 Seropédica RJ, Brazil \\ Correspondence should be addressed to José C. F. Alves, alvesjcf@yahoo.com.br \\ Received 29 September 2010; Accepted 4 November 2010 \\ Academic Editor: Emmanuel Theodorakis \\ Copyright () 2010 José C. F. Alves. This is an open access article distributed under the Creative Commons Attribution License, \\ which permits unrestricted use, distribution, and reproduction in any medium, provided the original work is properly cited. \\ The sesquiterpene lactones guaia-1(10),11(13)-dieno- $4 \alpha$-hydroxy, $9 \alpha$-acetyl-15-iodine-12,6 $\alpha$-lactone (2), guaia-1(10),4(15),11(13)- \\ trieno-9 $\alpha$-hydroxy-12,6 $\alpha$-lactone (3), (11S)-guaia-4(15),10(14)-dieno-9 $\alpha$-hydroxy-13-methoxy-12,6 $\alpha$-lactone (4), (11S)-guai- \\ 1(10)-eno- $4 \alpha, 9 \alpha$-dihydroxy-13-methoxy-12,6 $\alpha$-lactone (5), and guaia-1(10),11(13)-dieno-4 $\alpha, 9 \alpha$-dihydroxy-15-iodine-12,6 $\alpha$-lac- \\ tone (6) were previously obtained starting from the natural product eremanthine (1). In this paper we report the catalytic \\ hydrogenation reactions of allylic derivatives $\mathbf{2}-\mathbf{5}$ and the methanol addition to $\alpha$-methylene- $\gamma$-lactone of the iodohydrin $\mathbf{6}$.
}

\section{Introduction}

In previous publications $[1,2]$ we reported the synthesis of allylic derivatives 2-6 from eremanthine (1) (Figure 1). As an extension to our studies on the chemical transformations of eremanthine, we decided to explore the reactivity of allylic derivatives $\mathbf{2}-\mathbf{5}$ in catalytic hydrogenation reactions $[3,4]$ as well as the methanol addition to $\alpha$-methylene- $\gamma$-lactone of the iodohydrin 6 . In this paper we present the results of the performed study aiming at to evaluate the reactivity of the mentioned reactions.

\section{Results and Discussion}

Eremanthine (1) is one of the principal sesquiterpene lactones obtained from the extracted oil of the pulverized trunk wood of the Brazilian plants Eremanthus elaeagnus [5] and Vanillosmopsis erythropappa [6, 7] (Eremanthus erythropappus) [8], and, therefore, it was available in sufficient amount to accomplish the sequence of reactions shown in Scheme 1.

2.1. Study of Catalytic Hydrogenation of the Allylic Derivatives 2-5. Catalytic hydrogenation of allylic acetate 2 (Scheme 1) led to hydrogenolysis of the bond C15-I and reduction of double bond C11-C13. The ${ }^{1} \mathrm{H}$ NMR spectrum showed a signal at $\delta 1.24(\mathrm{~d}, J 7.3 \mathrm{~Hz}, 3 \mathrm{H})$ relative to hydrogens of C-13 methyl group besides a signal at $\delta 1.28(\mathrm{~s}, 3 \mathrm{H})$ assigned for C-15 methyl group, the presence of a double doublet at $\delta 5.32(J 2.0$ and $4.9 \mathrm{~Hz})$ relative to hydrogen $\mathrm{C} 9-\mathrm{H}$, a singlet at $\delta 2.04$ relative to hydrogens of methyl at the acetate group, and a doublet at $\delta 1.73(J 0.9 \mathrm{~Hz})$ assigned for C-14 methyl group. The stereochemistry of C-13 methyl group was studied by theoretical calculations (molecular mechanic level, MM2) [9] and by NMR-comparison with the sesquiterpene lactones 16-19 (Figure 2) reported in the literature [10-15]. The theoretical calculations of relative stability of the two stereoisomers, using molecular mechanic tools (MM2 calculation) [16], showed that the C-13 methyl group should be in $\alpha$ position (Scheme 2 ).

In order to determine the probable intermediates and final products from the catalytic hydrogenation reaction of the allylic alcohol 3 we used the data of TLC, ${ }^{1} \mathrm{H}$ NMR, and ${ }^{13} \mathrm{C}$ NMR in combination with the calculations of steric energy performed by molecular mechanics (MM2). For a better understanding of stages involved in the transformation of allylic alcohol 3 into the mixture of isomers $8 \mathbf{a}$ and 8c (Scheme 1), we elaborate Scheme 3 containing all intermediates and all probable products from catalytic hydrogenation of compound 3 , with the respective steric 


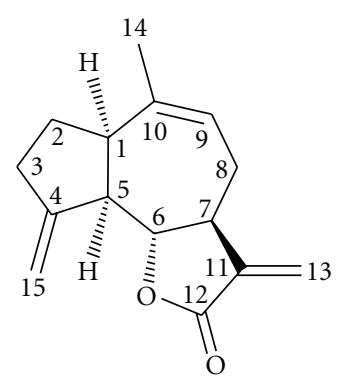

1

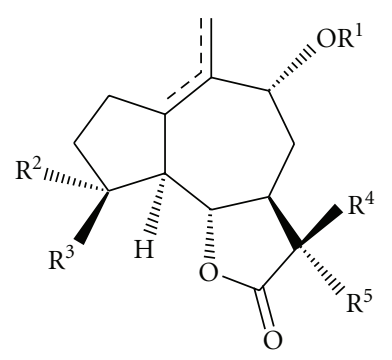

2: $\mathrm{R}^{1}=\mathrm{Ac} ; \mathrm{R}^{2}=\mathrm{OH} ; \mathrm{R}^{3}=\mathrm{CH}_{2} \mathrm{I} ; \mathrm{R}^{4}-\mathrm{R}^{5}=\mathrm{CH}_{2} ; \Delta^{1,10}$

3: $\mathrm{R}^{1}=\mathrm{H} ; \mathrm{R}^{2}-\mathrm{R}^{3}=\mathrm{CH}_{2} ; \mathrm{R}^{4}-\mathrm{R}^{5}=\mathrm{CH}_{2} ; \Delta^{1,10}$

4: $\mathrm{R}^{1}=\mathrm{H} ; \mathrm{R}^{2}-\mathrm{R}^{3}=\mathrm{CH}_{2} ; \mathrm{R}^{4}=\mathrm{H} ; \mathrm{R}^{5}=\mathrm{CH}_{2} \mathrm{OMe} ; \mathrm{C} 1-\mathrm{H} \alpha ; \Delta^{10,14}$

5: $\mathrm{R}^{1}=\mathrm{H} ; \mathrm{R}^{2}=\mathrm{OH} ; \mathrm{R}^{3}=\mathrm{CH}_{3} ; \mathrm{R}^{4}=\mathrm{H} ; \mathrm{R}^{5}=\mathrm{CH}_{2} \mathrm{OMe} ; \Delta^{1,10}$

6: $\mathrm{R}^{1}=\mathrm{H} ; \mathrm{R}^{2}=\mathrm{OH} ; \mathrm{R}^{3}=\mathrm{CH}_{2} \mathrm{I} ; \mathrm{R}^{4}-\mathrm{R}^{5}=\mathrm{CH}_{2} ; \Delta^{1,10}$

FIgURE 1: Eremanthine (1) and its allylic derivatives 2-6.

energies. After the time of hydrogenation $(3 \mathrm{~h})$, TLC revealed the total consumption of substrate $3\left(\mathrm{R}_{\mathrm{f}} 0.33\right.$, blue with $\mathrm{Ce}\left(\mathrm{SO}_{4}\right)_{2} / \mathrm{H}_{2} \mathrm{SO}_{4} /$ heat $)$ [17], the predominance of products with $\mathrm{R}_{\mathrm{f}} 0.70$ (orange) and a minimum amount of intermediates with $\mathrm{R}_{\mathrm{f}} 0.37$ (red) and $\mathrm{R}_{\mathrm{f}} 0.42$ (lilac). The crude product from the reaction was submitted to ${ }^{1} \mathrm{H}$ NMR and ${ }^{13} \mathrm{C}$ NMR and the spectra showed a complex profile. After a detailed spectral analysis, we could assign the signals shown at Table 1 and do some considerations on the probable course of the reaction. The absence at the ${ }^{1} \mathrm{H}$ NMR spectrum of signals relative to methylene from the $\gamma$-lactone and the presence of signals with almost imperceptible intensity at $\delta$ $5.40-5.30 \mathrm{ppm}$, characteristic of the two olefinic hydrogens $\mathrm{C} 15-\mathrm{H}$, confirmed the better reactivity of double bond $\mathrm{C} 11-\mathrm{C} 13$ in relation to $\mathrm{C} 4-\mathrm{C} 15$ on the compound 3. The detection of three signals, at the ${ }^{13} \mathrm{C}$ NMR spectrum $(\delta$ $77.64,77.00$ and $73.67 \mathrm{ppm}$ ), relative to allylic oxygenated carbons $\mathrm{C} 9-\mathrm{OH}$ suggests that the hydrogenation of double bond $\mathrm{C} 11-\mathrm{C} 13$ on the substrate 3 proceeded, as expected, by a stereoselective manner generating the intermediate 20 . However, the hydrogen addition to double bond C4-C15 on that intermediate was processed for both $\alpha$ and $\beta$ faces generating a more stable substance (compound 22) in mixture with the less stable stereoisomer (compound 23). Thus, those three signals at the ${ }^{13} \mathrm{C}$ NMR spectrum, relative to oxygenated allylic carbons, were attributed to the carbons C9-OH of the intermediates 20, 22 and 23. This result was fundamental to determine the preferential course of the catalytic hydrogenation reaction from the substrate 3 , in combination with the assignments for the carbons C-6 at the ${ }^{13} \mathrm{C}$ NMR spectrum. Thus, the seven signals detected at that spectrum $(\delta 89.98,89.07,86.49,86.28,85.85,83.10$ and $83.00 \mathrm{ppm}$ ) were attributed to the oxygenated carbons C-6 of the intermediates that did not totally react $(20,22$, 23, 26 and 27) in mixture with the final products $\mathbf{8 a}$ (major) and $\mathbf{8 c}$ (minor). The only signals easily assigned at the NMR spectra were those of higher intensity attributed to the major product $\mathbf{8 a}$ shown at Table 1. Therefore, with these spectral evidences and analysis of the probable isomers obtained in that reaction through the theoretical calculations from molecular mechanics (MM2) we can affirm that the majority product from the catalytic hydrogenation reaction of allylic alcohol $\mathbf{3}$ is the isomer $\mathbf{8 a}$. In that transformation process the substrate 3 should preferentially pass for the steps outlined in Scheme 4 to generate the more stable product $\mathbf{8 a}$ in mixture with the subproduct $\mathbf{8 c}$.

The analysis of catalytic hydrogenation reaction from allylic alcohol 4 by TLC (50\% EtOAc/hexane) after 1 hour of reaction (Scheme 1) revealed the total consumption of substrate $4\left(R_{f} 0.25\right.$, blue $)$ and formation of products $\left[R_{f}\right.$ 0.66 (brownish)]. The stages proposed for catalytic hydrogenation of the substrate $\mathbf{4}$ are outlined in Scheme 5. The ${ }^{1} \mathrm{H}$ NMR spectrum of product from catalytic hydrogenation of allylic alcohol 4 showed that the double bond C4-C15 and allylic system were totally hydrogenated, due to absence of characteristic signals of olefinic hydrogens and of the hydrogen attached to carbon $\mathrm{C} 9-\mathrm{OH}$. The spectral data of the generated product were in agreement with the formation of the lactones $\mathbf{1 1}$ and $\mathbf{1 2}$ previously described in [2] in a respective proportion of $(5: 1)$, in mixture with traces of more two lactones characterized as $\mathbf{1 3}$ and $\mathbf{1 4}$ in previously described [2]. This proportion was measured by the integrals relative to signals at $\delta 3.75(\mathrm{t}, J 10.0 \mathrm{~Hz}, \mathrm{C} 6-\mathrm{H}$ of majority product) and $\delta 4.01$ ( $\mathrm{t}, J 9.6 \mathrm{~Hz}, \mathrm{C} 6-\mathrm{H}$ of minority product). The multiplets at $\delta 4.10$ and $4.37 \mathrm{ppm}$ were, respectively, attributed to lactonic hydrogens $\mathrm{C} 6-\mathrm{H}$ of minority products 13 and 14. The stereochemistry of methyl groups $\mathrm{C} 14-\mathrm{H}$ and $\mathrm{C} 15-\mathrm{H}$ on the majority product $\mathbf{1 1}$ was determined by experiment of intramolecular Nuclear Overhauser Effect (NOE): irradiation of $\mathrm{C} 15-\mathrm{H}$ methyl group at $\delta 1.09$ showed an enhancement of $\mathrm{C} 5-\mathrm{H}$ sinal ( $\alpha$ position) at $\delta 1.92(10 \%)$ and an enhancement of $\mathrm{C} 14-\mathrm{H}$ signal of methyl group at $\delta$ 0.93 (5\%), indicating that the methyls $\mathrm{C} 14-\mathrm{H}$ and $\mathrm{C} 15-\mathrm{H}$ are both in $\alpha$ position.

The transformation of allylic alcohol 5 into compound 9 has been previously described in a satisfactory manner through catalytic hydrogenation ( 55 psi of $\mathrm{H}_{2}, 10 \% \mathrm{Pd}-\mathrm{C}$, $\mathrm{EtOH}$, r. t., $30 \mathrm{~min}$ ) [1]. In this paper we report the results 


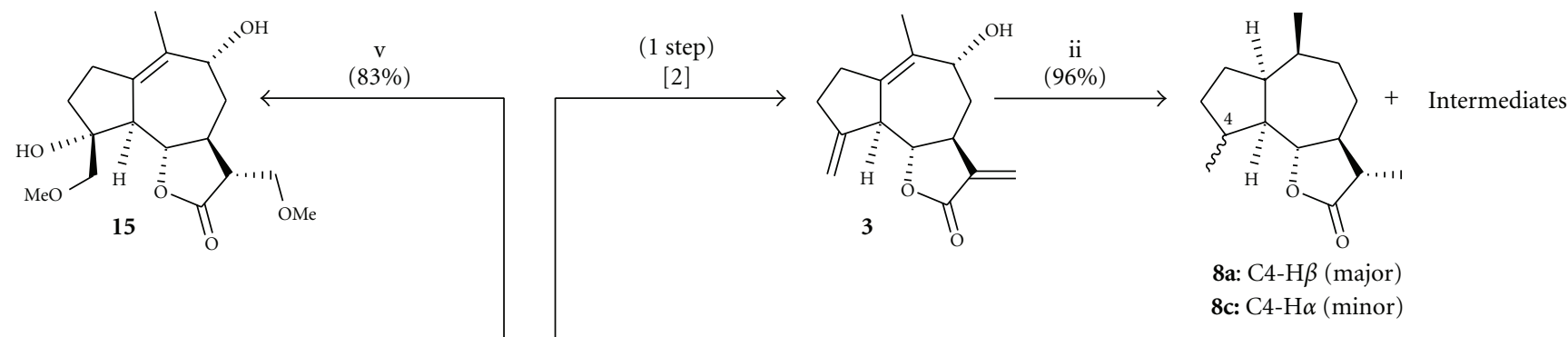

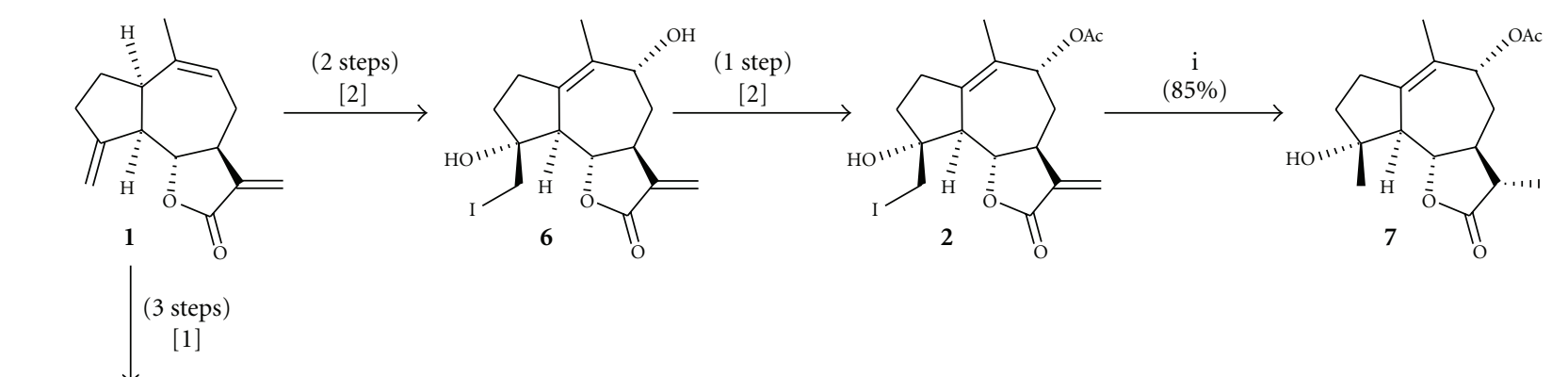

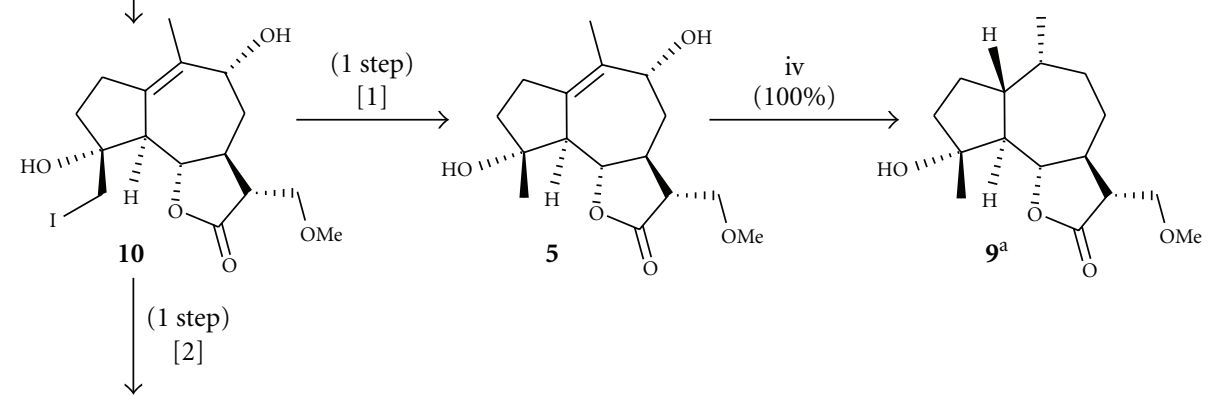

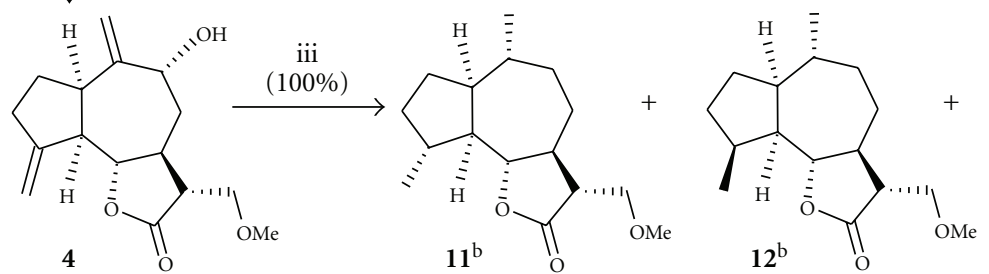

$(5: 1)$

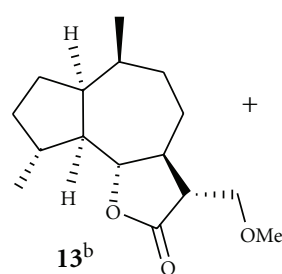

(traces)

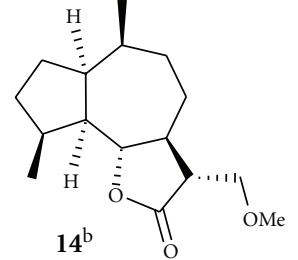

(traces)

Scheme 1: Reagents and conditions: (i) $\mathrm{H}_{2}$ (50 psi), 10\% Pd-C (0.1 equiv), EtOH (r. t., 5 h); (ii) $\mathrm{H}_{2}$ (40 psi), $10 \%$ Pd-C (0.1 equiv), EtOH (r. t., 3 h); (iii) $\mathrm{H}_{2}$ (30 psi), 10\% Pd-C (0.1 equiv), EtOH (r. t., 1 h); (iv) $\mathrm{H}_{2}$ (5 psi), $10 \%$ Pt-C (0.1 equiv), EtOH (r. t., 30 min); (v) MeONa-MeOH

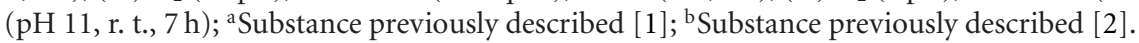

TABLe 1: Selected chemical shifts for the hydrogens and carbons of compounds 20, 22, 23, 26, 27, 8a and $8 \mathrm{c}$.

\begin{tabular}{|c|c|c|c|c|c|c|c|c|}
\hline \multirow{2}{*}{ Compound } & \multicolumn{6}{|c|}{ Hydrogens [ $\delta$ (Multiplicity, $J / \mathrm{Hz}$ )] } & \multirow{2}{*}{${ }^{13} \mathrm{C}\left(\mathrm{sp}^{2}\right) \delta$} & \multirow{2}{*}{${ }^{13} \mathrm{C}\left(\mathrm{sp}^{3}\right) \delta$ (Position) } \\
\hline & H-5 & H-6 & H-9 & H-13 & H-14 & H-15 & & \\
\hline & $3.57(\mathrm{~m})$ & $4.14(t, 10.0)$ & $4.50-4.20(\mathrm{~m})$ & $1.30-1.00(\mathrm{~m})$ & $1.86(\mathrm{sl})$ & $5.40-5.30(\mathrm{~m})$ & 144.00 & $89.98(\mathrm{C}-6)$ \\
\hline & $2.89(\mathrm{~m})$ & $4.05-3.85(\mathrm{~m})$ & & & $1.81(\mathrm{sl})$ & $1.30-1.00(\mathrm{~m})$ & 138.25 & $86.49(\mathrm{C}-6)$ \\
\hline & $2.63(\mathrm{~m})$ & $4.04(t, 9.2)$ & & & $1.69(\mathrm{sl})$ & & 131.25 & $86.28(\mathrm{C}-6)$ \\
\hline $20,22,23$ & $2.50(\mathrm{~m})$ & $3.81(\mathrm{t}, 9.5)$ & & & $0.91(\mathrm{~d}, 7.1)$ & & & $85.85(\mathrm{C}-6)$ \\
\hline \multirow[t]{5}{*}{$26,27,8 c$} & & $3.65(\mathrm{~m})$ & & & & & & $83.10(\mathrm{C}-6)$ \\
\hline & & & & & & & & $83.00(\mathrm{C}-6)$ \\
\hline & & & & & & & & $77.64(\mathrm{C}-9)$ \\
\hline & & & & & & & & $77.00(\mathrm{C}-9)$ \\
\hline & & & & & & & & $73.67(\mathrm{C}-9)$ \\
\hline $8 a$ & - & $3.72(\mathrm{dd}, 9.7,9.9)$ & - & $1.14(\mathrm{~d}, 6.9)$ & $0.91(\mathrm{~d}, 7.1)$ & $1.09(\mathrm{~d}, 6.4)$ & 182.15 & $89.07(\mathrm{C}-6)$ \\
\hline
\end{tabular}




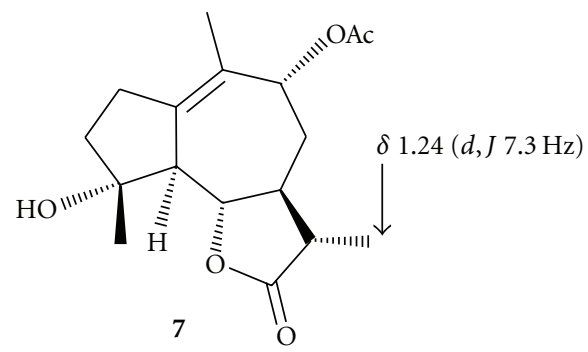

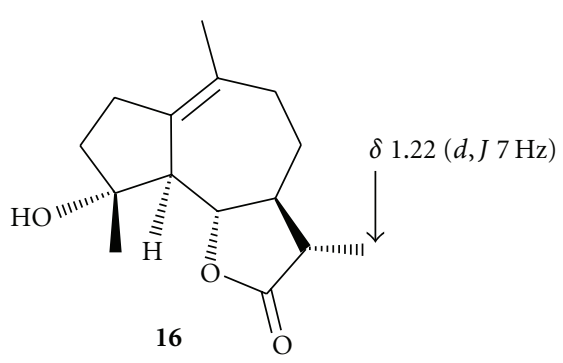

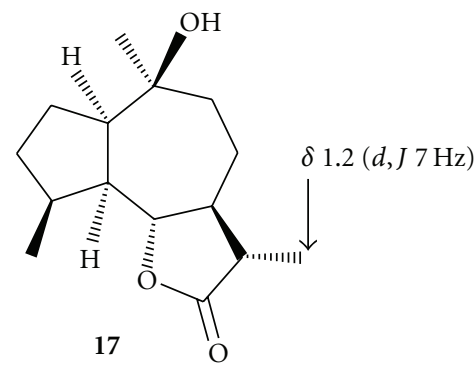

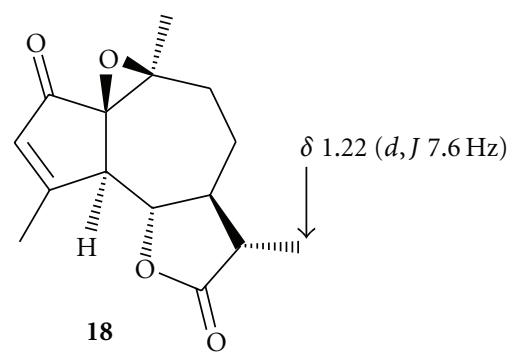

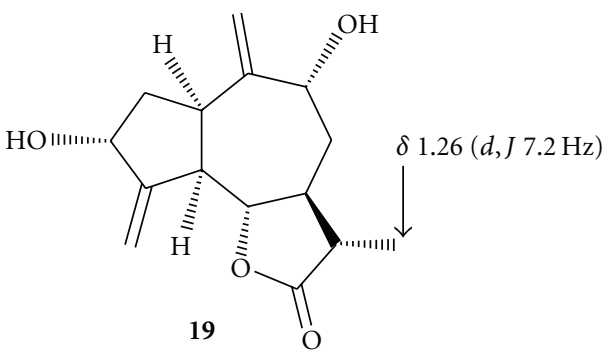

Figure 2<smiles>CC(=O)O[C@H]1C[C@H]2[C@H](OC(=O)[C@@H]2C)[C@@H]2C(=C1C)CC[C@@H]2C</smiles>

$\mathrm{SE}=34.763$

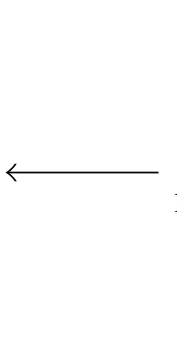<smiles>C=C1C(=O)O[C@H]2[C@@H]1C[C@@H](OC(C)=O)C(C)=C1CC[C@](O)(CI)[C@H]12</smiles>

$\mathrm{SE}=$ Steric energy $\left(\mathrm{kcal} \mathrm{mol}^{-1}\right)$

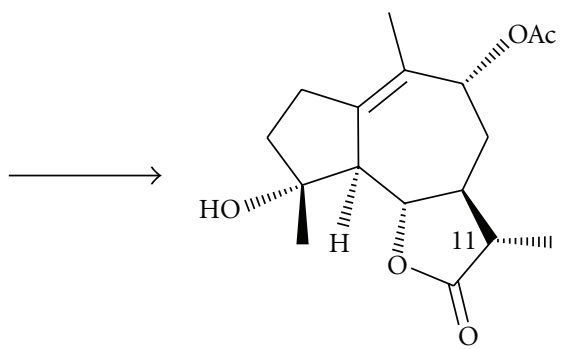

7

$\mathrm{SE}=33.49$

Scheme 2

modifying the hydrogen pressure and the reaction catalyst. Therefore, the substrate $\mathbf{5}$ was submitted to catalytic hydrogenation with the use of 5 psi of $\mathrm{H}_{2}, 10 \% \mathrm{Pt}-\mathrm{C}$ as the catalyst and $\mathrm{EtOH}$ as the solvent of reaction, accomplished at room temperature (Scheme 1). After 30 minutes, the mixture was submitted to analysis by TLC. The plate of TLC was eluted 3 times with 50\% EtOAc/hexane aiming to verify if there was still the intermediate with double bond $\mathrm{C} 1-\mathrm{C} 10$ $\left(\mathrm{R}_{\mathrm{f}}\right.$ 0.44) that is formed after hydrogenolysis of the bond $\mathrm{C}-\mathrm{OH}$, as reported in previous publication [1], and that reveals in solution of ceric sulfate with lilac coloration. We evidenced the presence of just a stain of orange coloration $\left(R_{f}\right.$ 0.41 ), characteristic of the final product 9 from that reaction. The ${ }^{1} \mathrm{H}$ NMR spectrum of the isolated product showed similar spectral characteristics to the ones of compound 9 previously described in [1]. An important datum regarding the synthesis of compound 9 refers to epimeric purity of substrate 5 at C-11 position. It was verified in the stage of isolation of compound 5 that the heating of that substance in EtOAc on the rotatory evaporator generated a very small 


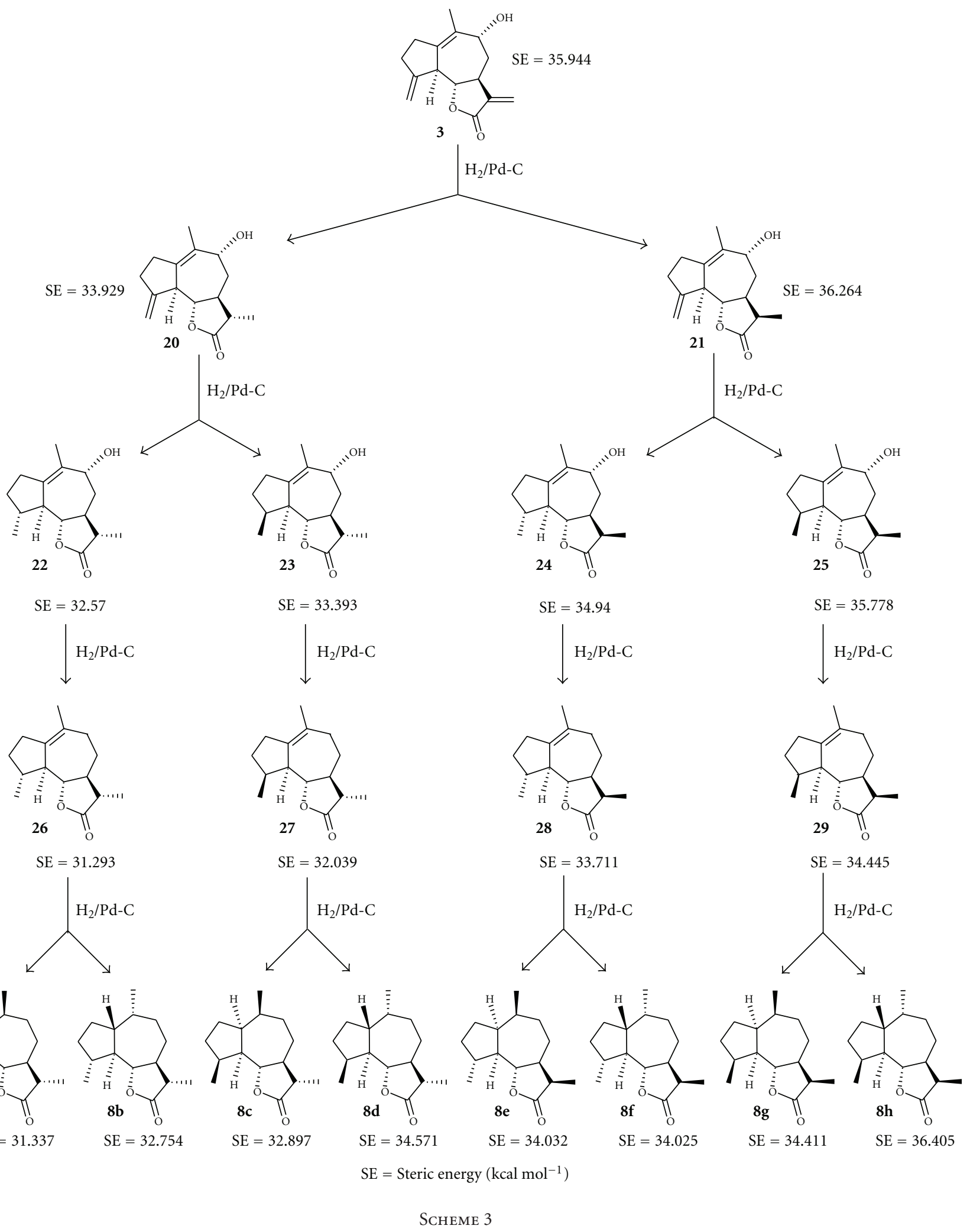

amount of a product with lightly superior $\mathrm{R}_{\mathrm{f}}$, characteristic of epimer from the substance $\mathbf{5}$ at $\mathrm{C}-11$ position. This epimer was detected at the ${ }^{1} \mathrm{H}$ NMR spectrum of the substance 5 by a very small singlet at $\delta 3.28 \mathrm{ppm}$, relative to methoxyl of the $\beta$-oriented group $\mathrm{CH}_{2} \mathrm{OMe}$ at $\mathrm{C}$-11. In certain occasion we performed an experiment of catalytic hydrogenation with a fraction of $17 \mathrm{mg}$, obtained from the purification by column chromatography of allylic alcohol 


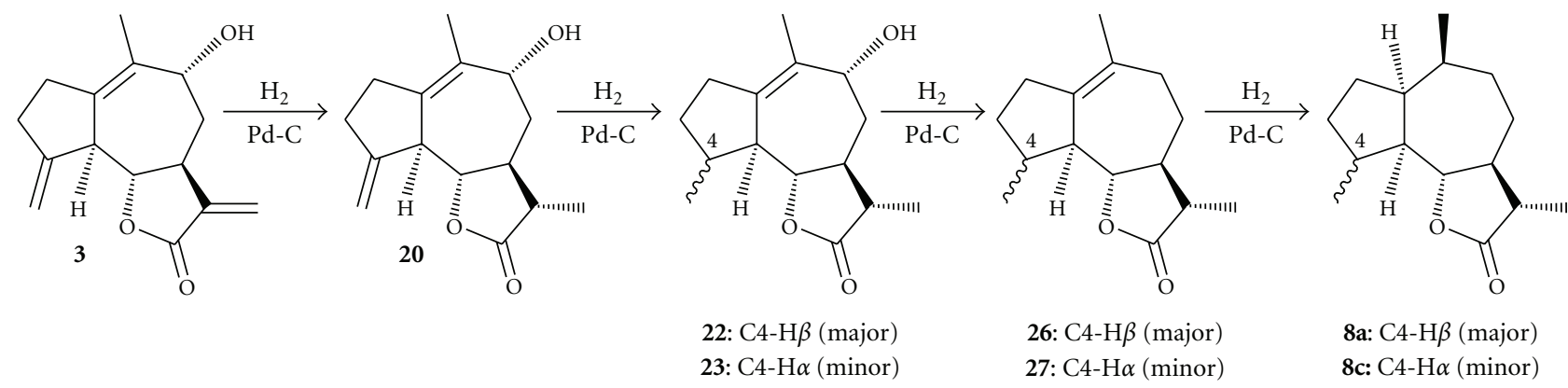

SCHEME 4

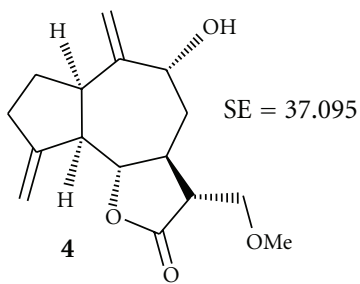

$\mathrm{H}_{2} / \mathrm{Pd}-\mathrm{C}$
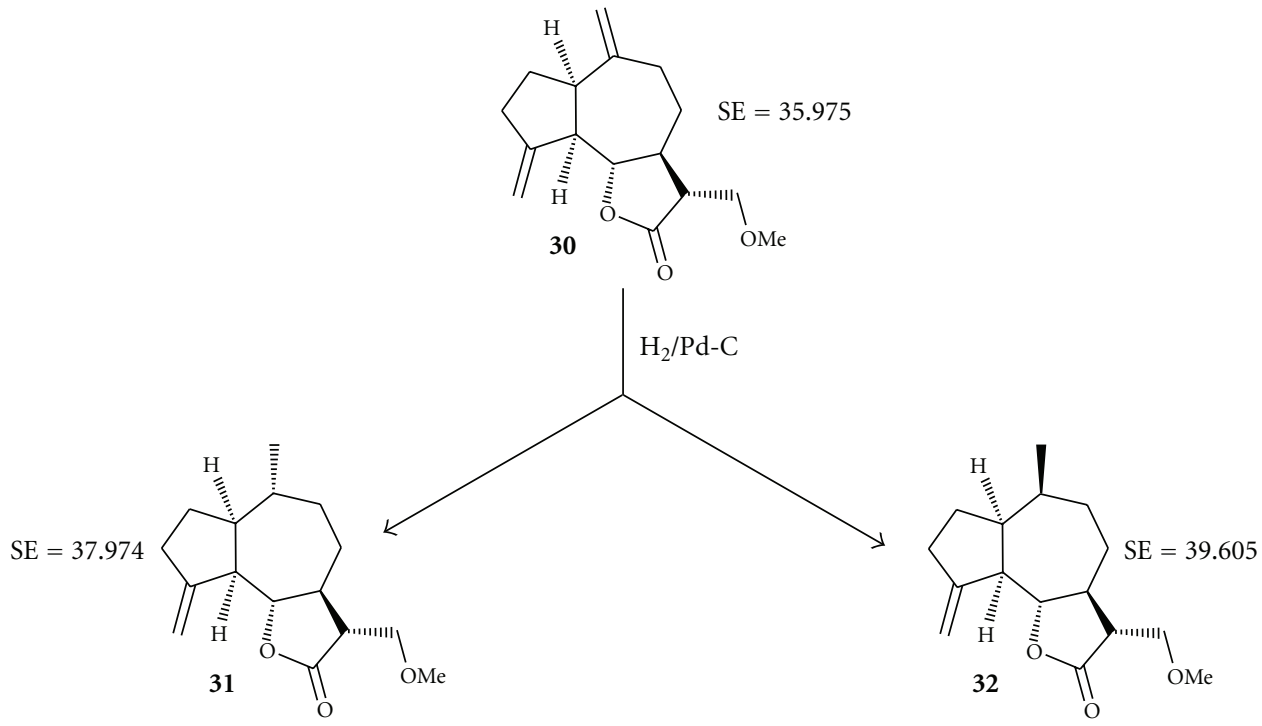

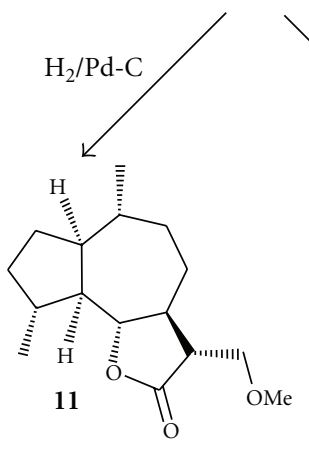

$\mathrm{SE}=39.041$

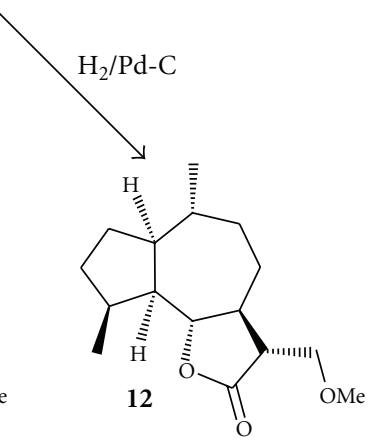

$\mathrm{SE}=40.304$

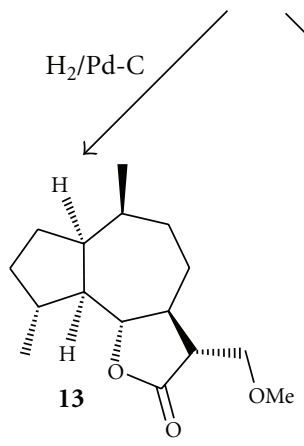

$\mathrm{SE}=39.275$

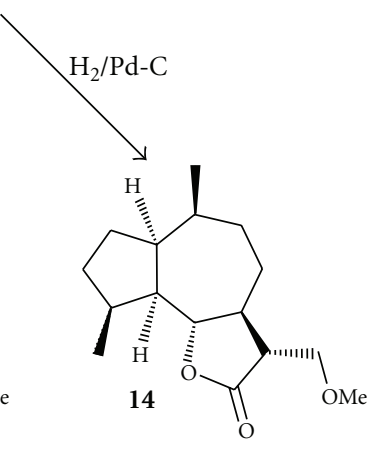

$\mathrm{SE}=40.967$

$\mathrm{SE}=$ Steric energy $\left(\mathrm{kcal} \mathrm{mol}^{-1}\right)$ 
TABLE 2: Selected chemical shifts for the hydrogens of isomers 34 and 35 .

\begin{tabular}{lcc}
\hline Hydrogens & \multicolumn{2}{c}{$\delta$ (multiplicity, J/Hz) } \\
& Isomer 34 & Isomer 35 \\
\hline $\mathrm{H}-6$ & $4.02(\mathrm{t}, 10.2)$ & $3.96(\mathrm{dd}, 9.8,10.7)$ \\
$\mathrm{H}_{\mathrm{a}}-13$ & $6.13(\mathrm{~d}, 3.5)$ & $6.27(\mathrm{~d}, 3.4)$ \\
$\mathrm{H}_{\mathrm{b}}-13$ & $5.41(\mathrm{~d}, 3.2)$ & $5.52(\mathrm{~d}, 3.1)$ \\
$\mathrm{H}-14$ & $0.96(\mathrm{~d}, 7.2)$ & $1.04(\mathrm{~d}, 6.6)$ \\
$\mathrm{H}-15$ & $1.34(\mathrm{~s})$ & $1.36(\mathrm{~s})$ \\
\hline
\end{tabular}

5, which contained an impurity of its epimer at the C-11 position $(1: 1)$ (Scheme 6). After the time of reaction, the crude product was isolated and then submitted to reaction of methanol elimination by previously described procedure [1]. The ${ }^{1} \mathrm{H}$ NMR spectrum of crude product from that reaction showed signals of the substance $1 R, 10 R$-dihydromicheliolide (34), described in previous publication [1], in mixture with the signals of other $\alpha$-methylene- $\gamma$-lactone characterized as $1 S, 10 S$-dihydromicheliolide (35), in the proportion of $(1: 1)$. This result suggests that the addition of hydrogen to double bond $\mathrm{C} 1-\mathrm{C} 10$ on allylic alcohols $\mathbf{5}$ and $\mathbf{3 3}$ is induced by the group $\mathrm{CH}_{2} \mathrm{OMe}$ attached to $\mathrm{C}-11$ position; in other words, if the group $\mathrm{CH}_{2} \mathrm{OMe}$ is in $\alpha$ position at $\mathrm{C}-11$, the hydrogen addition to double bond $\mathrm{C} 1-\mathrm{C} 10$ will take place for the $\beta$ face, as previously described in [1]. On the other hand, if the group $\mathrm{CH}_{2} \mathrm{OMe}$ is in $\beta$ position at $\mathrm{C}-11$, the addition of hydrogen will occur for the $\alpha$ face of that double bond. The main chemical shifts of the hydrogens at the ${ }^{1} \mathrm{H}$ NMR spectrum from the crude product of the reaction depicted in Scheme 6 are displayed in Table 2. The substances $\mathbf{3 4}$ and $\mathbf{3 5}$ are inseparable for column chromatography of silica gel due to their similar $\mathrm{R}_{\mathrm{f}}$.

\subsection{Evaluation of the Reactivity of Allylic System}

on the Compounds 2-5 in Catalytic Hydrogenation Reactions. Through the experimental results obtained in the catalytic hydrogenation reactions of allylic derivatives $\mathbf{2 - 5}$ we could compare the reactivity of allylic system in the respective compounds. It was verified that the allylic system of compound 2 , constituted by double bond $\mathrm{C} 1-\mathrm{C} 10$ and the bond C9-OAc, was not hydrogenated. In the compound $\mathbf{3}$ that system was little reactive, unlike the compound 4 in which such system was totally hydrogenated. In the compound $\mathbf{5}$ that system was strongly reactive, as previously verified with the use of the $\mathrm{Pd}$ catalyst [1] and also in the experimental results of this paper, in which Pt was used as catalyst. Starting from these observations, we elaborated the models shown at Figure 3 containing the probable reactive complexes that should be formed among the allylic derivatives $\mathbf{2}-\mathbf{5}$ and the catalysts used in the mentioned reactions.

For allylic acetate $\mathbf{2}$ we elaborate the reactive complex 2a, whose complexation of the catalyst (Pd) should preferentially occur with the $\mathrm{sp}^{2}$ oxygen of acetate group that possess high electronic density, and not with the $\mathrm{sp}^{3}$ oxygen of the bond that would be hydrogenolysed (C9-OAc). The formation of that complex with the $\mathrm{sp}^{2}$ oxygen of $\mathrm{C}=\mathrm{O}$ and the bond $\mathrm{C} 1-\mathrm{C} 10$ should disfavor the hydrogenolysis of the bond C9-OAc turning it to no reactive, as observed in experimental results. The absence of product formed by the catalytic hydrogenation reaction of double bond C1-C10 can be related to the difficulty to hydrogenate a tetrasubstituted double bond. For the compounds 3-5 we elaborate the models of reactive complexes $\mathbf{3 a}-\mathbf{5 a}$ in which the catalyst is complexed with the respective double bonds and the oxygens of their allylic systems. Those reactive $\pi$-allyl complexes [18] should favor the hydrogenolysis of the bond $\mathrm{C} 9-\mathrm{OH}$ and hydrogenation of the respective double bonds. The low reactivity experimentally observed with the allylic alcohol 3 can be related to the difficulty to hydrogenate a tetrasubstituted double bond. In the case of allylic alcohol 4, the high reactivity experimentally observed can be related to the facility to hydrogenate a disubstituted double bond. Concerning allylic alcohol 5, the extreme facility to hydrogenate the tetrasubstituted double bond by using the Pd catalyst, as previously described in [1], or the Pt catalyst used in the experiment described in this paper can be related to additional complexation of the catalyst that should occur between the oxygen of the hydroxy group at C-4 position and the oxygen of carboxy group of the lactonic ring at C-6 [19]. That additional complexation of the catalyst with the oxygens at C-4 and C- 6 should favor the polarization of tetrasubstituted double bond C1-C10, turning it extremely reactive with the reagent $\mathrm{H}_{2}$ adsorbed onto the surface of catalyst in the form of a pair of radical anions $\mathrm{H}^{*} \mathrm{H}$ [20].

It is important to mention in this point that, in previous catalytic hydrogenation experiment of allylic alcohol 10 [1], the allylic system was not hydrogenated when $\mathrm{NaOAc}$ was added to reactional mixture to minimize the action of strong acid (HI) formed during hydrogenolysis of the bond C15-I. In this case, the formation of product from hydrogenation of allylic system was insignificant, even if high hydrogen pressure was used during a long period of time [1]. For this exception, in which the allylic system was not hydrogenated, we elaborate the reactive complex $\mathbf{1 0 a}$ (Figure 3 ). In this case, the complexation of the catalyst (Pd) should preferentially occur with the acetate anion and not with the solvent of reaction $(\mathrm{EtOH})$. This type of complex should turn the catalyst less reactive to make the hydrogenolysis of the bond $\mathrm{C} 9-\mathrm{OH}$ and hydrogenation of tetrasubstituted double bond $\mathrm{C} 1-\mathrm{C} 10$. This kind of competition between solvent and ligand to form complexes with metals used as catalysts in hydrogenation reactions, as well as the decrease of the catalytic activity resultant from the alteration of electron density around the central atom of those complexes, was discussed in review articles $[3,4]$.

2.3. Study of Methanol Addition to $\alpha$-Methylene- $\gamma$-Lactone of the Iodohydrin 6. It has been previously shown that $\mathrm{MeOH}$ can be additioned satisfactorily to $\alpha$-methylene- $\gamma$-lactone of eremanthine (1) using solution of $\mathrm{MeONa} / \mathrm{MeOH}$, prepared from $\mathrm{MeOH}$ and $\mathrm{Na}$ [1]. This conjugate addition reaction was performed in nearly quantitative yield and now we wish to report the result of this reaction accomplished with the iodohydrin 6 . It was verified through analysis by TLC 
<smiles>[CH][C@@]12C(=C(C)[C@@H](O)C[C@@H]3[C@@H](COC)C(=O)O[C@@H]31)CC[C@@H]2O</smiles>

$5^{\mathrm{a}}$

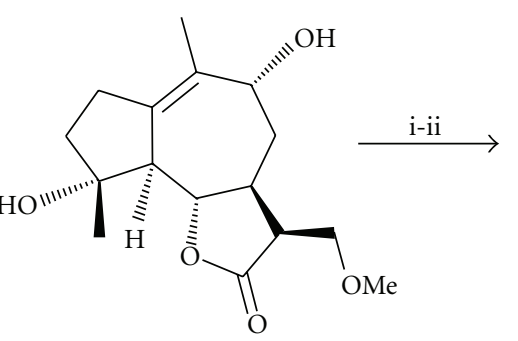

33

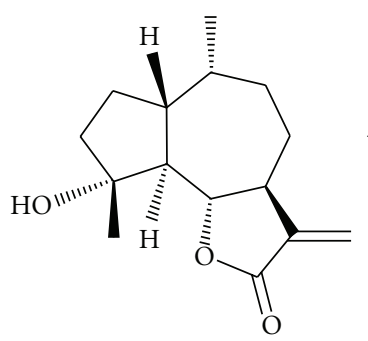

$34^{\mathrm{a}}$

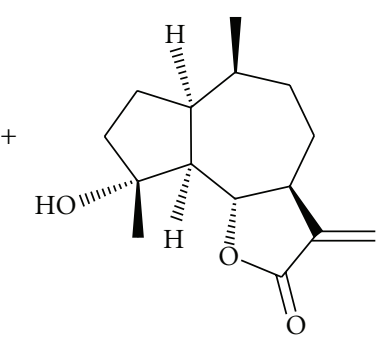

35

$(1: 1)$

$(1: 1)$

Scheme 6: Reagents and conditions: (i) $\mathrm{H}_{2}$ (55 psi), 10\% Pd-C (0.1 equiv), EtOH (r. t., 30 min); (ii) $4 \mathrm{~mol} \mathrm{~L}^{-1} \mathrm{NaOH}$ (5.5 equiv), DMF (reflux, $2.5 \mathrm{~h}$ ). The experimental procedures for the sequence of reactions described in this scheme are similar to the ones previously described in [1], using only the isomer 5 as starting material. a Substance previously described in [1].

(50\% EtOAc/hexane) from the reaction of iodohydrin $\mathbf{6}$ with a solution of $\mathrm{MeONa}$ in $\mathrm{MeOH}$, after $7 \mathrm{~h}$ (Scheme 1), the consumption of substrate $6\left(\mathrm{R}_{\mathrm{f}} 0.16\right.$, blue) and formation of product $\left[\mathrm{R}_{\mathrm{f}} 0.08\right.$ (blue)]. The ${ }^{1} \mathrm{H}$ NMR spectrum of the isolated product was in agreement with the formation of dimethoxylated compound 15, resultant from methanol addition to $\alpha$-methylene- $\gamma$-lactone and nucleophilic substitution at $\mathrm{C}-15$ position. The presence of doublets with very small intensity at $\delta 6.19$ and $5.48 \mathrm{ppm}$, relative to olefinic hydrogens $\mathrm{C} 13-\mathrm{H}$, confirmed that the nucleophilic substitution at the $\mathrm{C}-15$ position proceeded in a faster way than the methanol addition to $\alpha$-methylene- $\gamma$-lactone. The singlets with same intensity at $\delta 3.36$ and $3.34 \mathrm{ppm}$ were attributed to the 6 hydrogens of two methoxyl groups. The stereochemistry at C-11 position on the product 15 was determined through the coupling constants of the signal of hydrogen $\mathrm{C} 11-\mathrm{H}(\delta 2.42)$; an axial-axial interaction was verified between $\mathrm{C} 11-\mathrm{H}$ and $\mathrm{C} 7-\mathrm{H}(J 12.3 \mathrm{~Hz})$ and two equatorial-equatorial interactions between $\mathrm{C} 11-\mathrm{H}$ and the hydrogens $\mathrm{C} 13-\mathrm{H}(\mathrm{J} 4.8$ and $4.2 \mathrm{~Hz})$.

\section{Conclusions}

In summary, we could verify the reactivity and stereoselectivity on studied addition reactions through the results obtained in this work. The catalytic hydrogenation of $\alpha$-methylene- $\gamma$ lactone from allylic acetate 2 proceeded by a stereoselective manner with simultaneous hydrogenolysis of the bond C15-I resulting in the synthesis of the new eremanthine derivative 7. The absence of hydrogenolysis reaction on allylic system of acetate 2 in opposition to total hydrogenation of the mentioned system on allylic alcohol $\mathbf{5}$ suggests the use of acetate as protective group for allylic alcohols in similar guaianolides during catalytic hydrogenation reactions. After a detailed spectral analysis in combination with theoretical calculations of molecular mechanics (MM2), we propose the stages involved in the catalytic hydrogenation reaction of allylic alcohol 3 with formation of the final products 8a (major) and 8c (minor). The lactone $\mathbf{1 1}$ was obtained from allylic alcohol 4 , with high stereoselectivity in relation to previous experiment [2] in which the methanol adduct of eremanthine was used as substrate. The unequivocal attribution of the stereochemistry of methyl groups $\mathrm{C} 14-\mathrm{H}$ and $\mathrm{C} 15-\mathrm{H}$ of $\mathbf{1 1}$ was determined through experiment of intramolecular Nuclear Overhauser Effect (NOE). The synthesis of compound $\mathbf{9}$ in softer conditions of hydrogen pressure ( $5 \mathrm{psi}$ ) than the ones previously used (55 psi) [1], suggests the use of $\mathrm{Pt}-\mathrm{C}$ as preferential catalyst for that reaction. It was verified that the hydrogen addition to double bond $\mathrm{C} 1-\mathrm{C} 10$ on allylic alcohol 5 is induced by the group $\mathrm{CH}_{2} \mathrm{OMe}$ attached to carbon $\mathrm{C}-11$. This was confirmed when the reaction was accomplished with a mixture of allylic alcohol 5 and its epimer at C-11 position (33). The product from that reaction, after methanol elimination, generated a mixture characterized as $1 R, 10 R$-dihydromicheliolide (34), previously described in [1], and the new eremanthine derivative $1 S, 10 S$-dihydromicheliolide (35). For the stage of catalytic hydrogenation from allylic alcohols $3-5$, we propose the formation of $\pi$-allyl complexes as reactive intermediates of those reactions. The high reactivity of tetrasubstituted double bond $\mathrm{C} 1-\mathrm{C} 10$ on allylic alcohol $\mathbf{5}$ was attributed to additional complexation of the catalyst at the oxygenated positions C-4 and C-6, turning that tetrasubstituted double bond highly polarized. The comparison of the high reactivity from allylic alcohol $\mathbf{5}$ in relation to the low reactivity on allylic system of compound $\mathbf{1 0}$ reported in previous publication [1] in which $\mathrm{NaOAc}$ was used in the reaction mixture led us to deduce that the acetate anion displaces EtOH from the complex initially formed with the catalyst. The addition of a ligand to reaction mixture, containing an electron-withdrawing group ( $\mathrm{AcO}-)$, should alter the electronic density around the central atom of the complex turning the catalyst less reactive. The methanol addition to $\alpha$-methylene- $\gamma$-lactone of iodohydrin 6 resulted in the formation of a single product characterized as the new eremanthine derivative 15.

\section{Experimental}

NMR spectra were recorded on a Bruker AC-200 $\left({ }^{1} \mathrm{H}\right.$ : $200 \mathrm{MHz}$ and ${ }^{13} \mathrm{C}: 50.3 \mathrm{MHz}$ ) spectrometer. $\mathrm{CDCl}_{3}$ was used as the solvent and TMS as internal standard. Coupling 


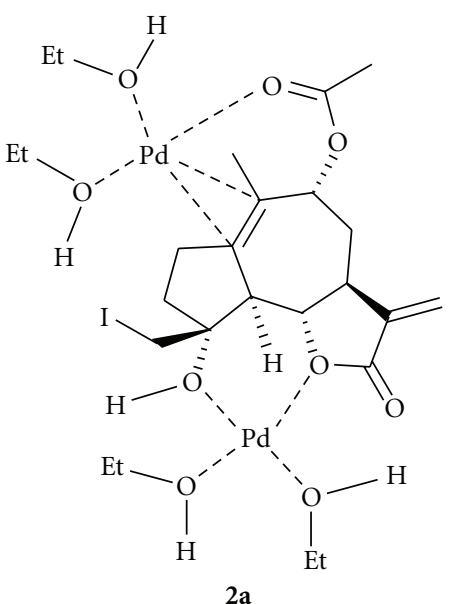

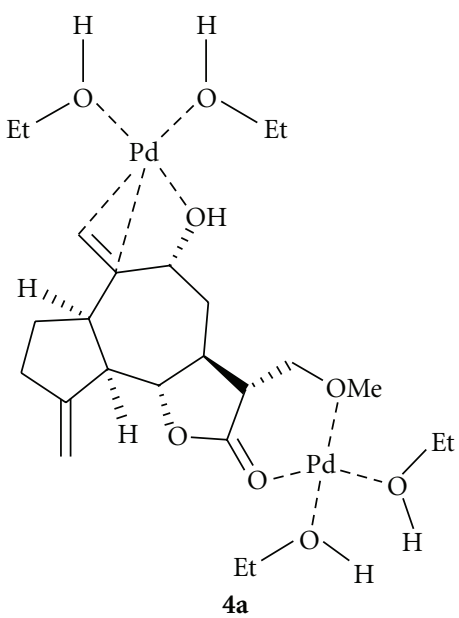

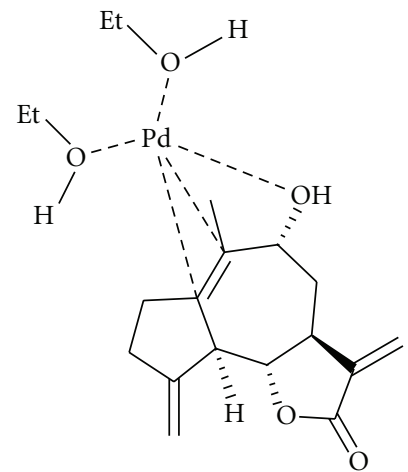

3a

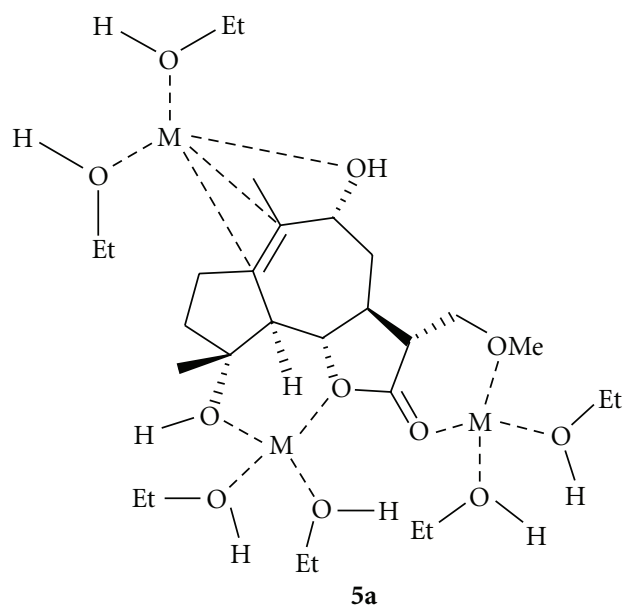

$\mathrm{M}=\operatorname{Metal}(\mathrm{Pd}$ or $\mathrm{Pt})$

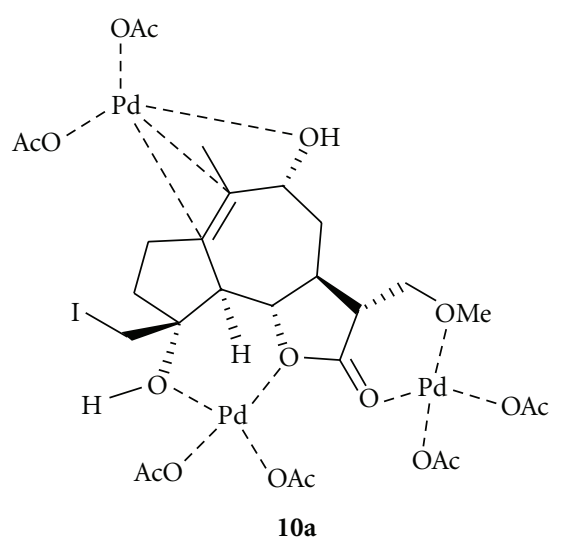

FIGURE 3

constants $(J)$ are reported in Hertz $(\mathrm{Hz})$. Multiplicities are indicated as s (singlet), bs (broad singlet), d (doublet), $\mathrm{t}$ (triplet), m (multiplet), dd (double doublet), and ddd (doublet of a double doublet). Assignment of the hydrogens for the substance $\mathbf{1 5}$ was made with base on the Homonuclear Correlation Spectra ${ }^{1} \mathrm{H} \times{ }^{1} \mathrm{H}-\mathrm{COSY}$. The spectrum of intramolecular Nuclear Overhauser Effect (NOE) was obtained by spectral difference, subtracting the spectrum registered with irradiation in the frequencies of absorption of the hydrogen atoms from that obtained with irradiation in region free of absorption. Thin layer chromatography was performed on aluminium sheets coated with $60 \mathrm{~F}_{254}$ 
silica. Visualization of the substances on the plates of TLC was accomplished spraying them with $2 \% \mathrm{Ce}\left(\mathrm{SO}_{4}\right)_{2}$ in $2 \mathrm{~mol} \mathrm{~L}^{-1} \mathrm{H}_{2} \mathrm{SO}_{4}$ and subsequent heating. Purifications and isolations for column chromatography were performed with silica gel (230-400 mesh). The eluent mixtures, used in the chromatographic separations, were prepared volume to volume $(\mathrm{v} / \mathrm{v})$ and are expressed in percentage $(\%)$. The values of $R_{f}$ from the studied substances were measured to evaluate the polarity differences, at TLC, of the obtained compounds. Solvents and reagents were dried and purified by the usual methods [21]. Hydrogenations were carried out using a Parr apparatus.

\subsection{General Procedure for the Catalytic Hydrogenation}

Reactions of Allylic Derivatives 2-5. A general procedure is described for the catalytic hydrogenation reaction of allylic acetate 2. A mixture of compound $2(0.020 \mathrm{~g}, 0.046 \mathrm{mmol})$, $\mathrm{EtOH}(1.5 \mathrm{~mL})$ and $10 \% \mathrm{Pd}-\mathrm{C}(0.005 \mathrm{~g}, 0.0046 \mathrm{mmol})$ at room temperature, was shaken with hydrogen ( $50 \mathrm{psi}$ ) in a Parr apparatus during $5 \mathrm{~h}$. The consumption of substrate was accompanied by reduction of hydrogen pressure on the reaction middle and TLC. After the reaction time the mixture was filtered, $\mathrm{H}_{2} \mathrm{O}(15 \mathrm{~mL})$ was added, and then concentrated in vacuum. The concentrated mixture was extracted with EtOAc $(1 \times 20 \mathrm{~mL})$ and then the organic extract was washed with aqueous $5 \% \mathrm{NaHCO}_{3}(1 \times 15 \mathrm{~mL})$, aqueous $5 \% \mathrm{Na}_{2} \mathrm{~S}_{2} \mathrm{O}_{3}$ $(1 \times 15 \mathrm{~mL})$, and again with $\mathrm{H}_{2} \mathrm{O}(1 \times 15 \mathrm{~mL})$. The organic layer was separated, and the aqueous phases were extracted with EtOAc $(1 \times 20 \mathrm{~mL})$. The organic extracts were dried with $\mathrm{Na}_{2} \mathrm{SO}_{4}$, filtered, and concentrated in vacuum. Crude product was filtered over column chromatography of silica gel eluted with 50\% EtOAc/hexane. It was obtained allylic acetate $7(0.012 \mathrm{~g}, 85 \%)$ as a colourless oil. $\mathrm{R}_{\mathrm{f}} 0.25$ (lilac) (50\% EtOAc/hexane). ${ }^{1} \mathrm{H} \mathrm{NMR}\left(\mathrm{CDCl}_{3}\right.$, partial assignment): $\delta 5.32(\mathrm{dd}, J 2.0$ and $4.9 \mathrm{~Hz}, 1 \mathrm{H}, \mathrm{H}-9), 3.87$ (dd, $J 10.2$ and $10.5 \mathrm{~Hz}, 1 \mathrm{H}, \mathrm{H}-6), 2.81$ (m, 1H, H-5), 2.70-1.00\{21H [2.04 $\left(\mathrm{s}, \mathrm{OCOCH}_{3}\right), 1.73$ (d, J 0.9 Hz, H-14), 1.28 (s, H-15), 1.24 (d, J $7.3 \mathrm{~Hz}, \mathrm{H}-13)]\}$.

4.2. Catalytic Hydrogenation Reaction of Allylic Alcohol 3. The reaction was executed following general procedure, using 3 (0.020 g, $0.081 \mathrm{mmol})$, EtOH $(2.0 \mathrm{~mL}), 10 \% \mathrm{Pd}-\mathrm{C}(0.009 \mathrm{~g}$, $0.0081 \mathrm{mmol})$, and hydrogen $(40 \mathrm{psi})$. After the time of reaction $(3 \mathrm{~h})$, the mixture was filtered and concentrated in vacuum. It was obtained a colourless oil ( $0.018 \mathrm{~g}, 96 \%)$ containing a majority product characterized as the compound $\mathbf{8} \mathbf{a}$ in mixture with other minority substances, characterized as intermediates of reaction that not totally react $(\mathbf{2 0}, \mathbf{2 2}, \mathbf{2 3}$, 26 and 27) and the minority product $8 \mathrm{c}$. Characteristic of the majority product $\mathbf{8 a}: \mathrm{R}_{\mathrm{f}} 0.70$ (orange) (50\% EtOAc/hexane). Characteristics of the minority substances: $20\left[R_{f} \quad 0.37\right.$ (red)], 22 and 23 [ $\mathrm{R}_{\mathrm{f}} 0.42$ (lilac)], 26, 27 and $8 \mathrm{c}\left[\mathrm{R}_{\mathrm{f}} 0.70\right.$ (orange) (50\% EtOAc/hexane). The partial assignment for the hydrogens and carbons of the intermediates and final products from this reaction is displayed at the Table 1.

4.3. Catalytic Hydrogenation Reaction of Allylic Alcohol 4. The reaction was executed following general procedure, using 4 (0.100 g, $0.359 \mathrm{mmol})$, EtOH $(4.0 \mathrm{~mL}), 10 \% \mathrm{Pd}-\mathrm{C}$ $(0.038 \mathrm{~g}, 0.036 \mathrm{mmol})$, and hydrogen $(30 \mathrm{psi})$. After the time of reaction $(1 \mathrm{~h})$ the mixture was filtered and concentrated in vacuum. It was obtained a colourless oil $(0.095 \mathrm{~g}, 100 \%)$ characterized as the compound $\mathbf{1 1}$ and the subproduct $12(5: 1)$, in mixture with traces of the lactones 13 and 14. Characteristics of the majority product 11: $\mathrm{R}_{\mathrm{f}} 0.66$ (brownish) (50\% EtOAc/hexane); ${ }^{1} \mathrm{H}$ NMR $\left(\mathrm{CDCl}_{3}\right.$, partial assignment $): \delta 3.75(\mathrm{t}, J 10.0 \mathrm{~Hz}, 1 \mathrm{H}, \mathrm{H}-6), 3.62(\mathrm{~m}$, $2 \mathrm{H}, \mathrm{H}-13), 3.34\left(\mathrm{~s}, 3 \mathrm{H}, \mathrm{OCH}_{3}\right), 2.50-2.15(\mathrm{~m}, 2 \mathrm{H}, \mathrm{H}-7$ and H-11), 2.10-0.80 \{18H [1.92 (m, H-5), 1.09 (d, J $6.5 \mathrm{~Hz}, \mathrm{H}-15), 0.93$ (d, J 7.2 Hz, H-14)]\}. Characteristics of subproduct 12: $\mathrm{R}_{\mathrm{f}} 0.66$ (brownish) (50\% EtOAc/hexane); ${ }^{1} \mathrm{H}$ $\mathrm{NMR}\left(\mathrm{CDCl}_{3}\right.$, partial assignment): $\delta 4.01(\mathrm{t}, J 9.6 \mathrm{~Hz}, 1 \mathrm{H}$, H-6). Characteristics of the minority lactones 13 and 14: $\mathrm{R}_{\mathrm{f}} 0.66$ (brownish) (50\% EtOAc/hexane); ${ }^{1} \mathrm{H} \mathrm{NMR}\left(\mathrm{CDCl}_{3}\right.$, partial assignment): $\delta 4.10(\mathrm{~m}, 1 \mathrm{H}, \mathrm{H}-6$ of 13) and $\delta 4.37$ (m, 1H, H-6 of 14).

4.4. Catalytic Hydrogenation Reaction of Allylic Alcohol 5. The reaction was executed following general procedure, using 5 (0.006 g, $0.020 \mathrm{mmol})$, EtOH $(0.5 \mathrm{~mL}), 10 \% \mathrm{Pt}-\mathrm{C}$ $(0.004 \mathrm{~g}, 0.002 \mathrm{mmol})$ and hydrogen $(5 \mathrm{psi})$. After the time of reaction $(30 \mathrm{~min})$, the mixture was filtered and concentrated in vacuum. It was obtained a colourless oil $(0.006 \mathrm{~g}, 100 \%)$ characterized as the compound 9 previously described in [1]. $\mathrm{R}_{\mathrm{f}} 0.41$ (orange) (50\% EtOAc/hexane). ${ }^{1} \mathrm{H} \mathrm{NMR}\left(\mathrm{CDCl}_{3}\right.$, partial assignment): $\delta 3.99(\mathrm{t}, J 10.3 \mathrm{~Hz}, 1 \mathrm{H}, \mathrm{H}-6), 3.64(\mathrm{~m}$, $2 \mathrm{H}, \mathrm{H}-13), 3.32$ (s, 3H, $\left.\mathrm{OCH}_{3}\right), 2.50-2.25$ (m, 2H, H-7 and H-11), 2.25-0.80 \{18H [1.94 (dd, J 10.3 and $11.2 \mathrm{~Hz}, \mathrm{H}-5)$, 1.32 (s, H-15), 0.95 (d, J 7.2 Hz, H-14)]\}.

\subsection{Reaction of Methanol Addition to $\alpha$-Methylene- $\gamma$-Lactone of Iodohydrin 6}

4.5.1. Preparation of $\mathrm{NaOMe}$ Solution. To a round bottom flask with $\mathrm{MeOH}(10 \mathrm{~mL})$, at room temperature, sodium was added slowly until the solution reaches $\mathrm{pH} 11$.

4.5.2. Reaction of Iodohydrin 6 with NaOMe Solution. Iodohydrin $6(0.023 \mathrm{~g}, 0.059 \mathrm{mmol})$ was dissolved in the solution of $\mathrm{NaOMe}(2.0 \mathrm{~mL})$ recently prepared as described in the previous item 4.5.1. The mixture was left under magnetic stirring and room temperature for $7 \mathrm{~h}$. Aqueous $10 \%(\mathrm{v} / \mathrm{v}) \mathrm{HCl}$ was added dropwise until $\mathrm{pH} 3$, diluted with $\mathrm{H}_{2} \mathrm{O}(15 \mathrm{~mL})$, and then concentrated in vacuum. The concentrated mixture was transferred to a separatory funnel and then extracted with EtOAc $(3 \times 20 \mathrm{~mL})$. The organic extracts were dried with $\mathrm{Na}_{2} \mathrm{SO}_{4}$, filtered, and concentrated in vacuum. It was obtained the allylic alcohol 15 as a yellowish oil $(0.016 \mathrm{~g}, 83 \%) . \mathrm{R}_{\mathrm{f}} 0.08$ (blue) $(50 \%$ EtOAc/hexane). ${ }^{1} \mathrm{H}$ NMR $\left(\mathrm{CDCl}_{3}\right.$, partial assignment $): \delta$ 4.21 (m, 1H, H-9), 3.86 (t, J $10.6 \mathrm{~Hz}, 1 \mathrm{H}, \mathrm{H}-6), 3.67$ (d, J $4.3 \mathrm{~Hz}, 2 \mathrm{H}, \mathrm{H}-13), 3.43$ (m, 2H, H-15), 3.36 (s, 3H, $\mathrm{OCH}_{3}$ ), $3.34\left(\mathrm{~s}, 3 \mathrm{H}, \mathrm{OCH}_{3}\right), 3.10-2.70(\mathrm{~m}, 2 \mathrm{H}, \mathrm{H}-5$ and $\mathrm{H}-7), 2.70-$ $1.40\{12 \mathrm{H}[2.42$ (ddd, J 4.2, 4.8 and $12.3 \mathrm{~Hz}, \mathrm{H}-11$ ), 1.79 (bs, H-14)]\}. 


\section{Acknowledgments}

José C. F. Alves thanks FAPERJ and CNPq for the concession of the fellowships to develop the project "Chemical transformations of natural substances. I-Studies with eremanthine." Professor Dr. Edna C. Fantini (in memoriam) for the supervision and the department of Chemistry (UFRRJ) for the NMR spectra.

\section{References}

[1] J. C. F. Alves and E. C. Fantini, "Chemical transformations of eremanthine. Synthesis of micheliolide and 1(R),10(R)dihydromicheliolide," Journal of the Brazilian Chemical Society, vol. 16, no. 4, pp. 749-755, 2005.

[2] J. C. F. Alves and E. C. Fantini, "Study of the inversion reaction of the lactonic fusion on eremanthine derivatives," Journal of the Brazilian Chemical Society, vol. 18, no. 3, pp. 643-664, 2007.

[3] R. A. W. Johnstone, A. H. Wilby, and I. D. Entwistle, "Heterogeneous catalytic transfer hydrogenation and its relation to other methods for reduction of organic compounds," Chemical Reviews, vol. 85, no. 2, pp. 129-170, 1985.

[4] G. Brieger and T. J. Nestrick, "Catalytic transfer hydrogenation," Chemical Reviews, vol. 74, no. 5, pp. 567-580, 1974.

[5] W. Vichnewski and B. Gilbert, "Schistosomicidal sesquiterpene lactone from Eremanthus elaeagnus," Phytochemistry, vol. 11, no. 8, pp. 2563-2566, 1972.

[6] P. M. Baker, C. C. Fortes, E. G. Fortes et al., "Chemoprophylactic agents in schistosomiasis: eremanthine, costunolide, $\alpha$-cyclocostunolide and bisabolol," Journal of Pharmacy and Pharmacology, vol. 24, no. 11, pp. 853-857, 1972.

[7] P. D. D. B. Lima, M. Garcia, and J. A. Rabi, "Selective extraction of $\alpha$-methylene- $\gamma$-lactones. Reinvestigation of Vanillosmopsis erythropappa," Journal of Natural Products, vol. 48, no. 6, pp. 986-988, 1985.

[8] M. S. Silvério, O. V. Sousa, G. Del-Vechio-Vieira, M. A. Miranda, F. C. Matheus, and M. A. C. Kaplan, "Pharmacological properties of the ethanol extract from Eremanthus erythropappus (DC.) McLeisch (Asteraceae)," Brazilian Journal of Pharmacognosy, vol. 18, no. 3, pp. 430-435, 2008.

[9] K. Gundertofte, T. Liljefors, P. O. Norrby, and I. Pettersson, "A comparison of conformational energies calculated by several molecular mechanics methods," Journal of Computational Chemistry, vol. 17, no. 4, pp. 429-449, 1996.

[10] N. H. Fischer, Y. F. Wu-Shih, G. Chiari, F. R. Fronczek, and S. F. Watkins, "Molecular structure of a cis-decalin-type eudesmanolide and its formation from a guaianolide-1(10)epoxide," Journal of Natural Products, vol. 44, no. 1, pp. 104110, 1981.

[11] T. R. Govindachari, B. S. Joshi, and V. N. Kamat, "Structure of parthenolide," Tetrahedron, vol. 21, no. 6, pp. 1509-1519, 1965.

[12] T. R. Govindachari, B. S. Joshi, and V. N. Kamat, "Revised structure of parthenolide," Tetrahedron Letters, vol. 5, no. 52, pp. 3927-3933, 1964.

[13] A. Corbrella, P. Gariboldi, G. Jommi, F. Orsini, and G. Ferrari, "Structure and absolute stereochemistry of vanillosmin, a guaianolide from Vanillosmopsis erythropappa," Phytochemistry, vol. 13, no. 2, pp. 459-465, 1974.

[14] Z. Hassan, H. Hussain, V. U. Ahmad et al., "Absolute configuration of $1 \beta, 10 \beta$-epoxydesacetoxymatricarin isolated from
Carthamus oxycantha by means of TDDFT CD calculations," Tetrahedron Asymmetry, vol. 18, no. 24, pp. 2905-2909, 2007.

[15] F. Bitam, M. L. Ciavatta, E. Manzo, A. Dibi, and M. Gavagnin, "Chemical characterisation of the terpenoid constituents of the Algerian plant Launaea arborescens," Phytochemistry, vol. 69, no. 17, pp. 2984-2992, 2008.

[16] The calculations were performed using MM2 program from Cambridge Soft Corporation, minimizing energy to minimum RMS gradient of 0.100, CS Chem3D Ultra 7.0, Molecular Modeling and Analysis, Cambridge Soft Corporation, Cambridge, UK, 2001.

[17] Eremanthine and its derivatives reveal on TLC with varied colors using solution of $2 \% \mathrm{Ce}(\mathrm{SO} 4)_{2}$ in $2 \mathrm{~mol} \mathrm{~L}^{-1} \mathrm{H}_{2} \mathrm{SO}_{4}$ and subsequent heating.

[18] K. J. Szabó, "Nature of the interaction between $\beta$-substituents and the allyl moiety in ( $\eta^{3}$-allyl)palladium complexes," Chemical Society Reviews, vol. 30, no. 2, pp. 136-143, 2001.

[19] E. C. Fantini, J. L. P. Ferreira, and J. A. Rabi, "Metal ion promoted methanolysis of sesquiterpene lactones leading to $\mathrm{O}^{6,15}$-cycloguaiane methyl esters," Journal of Chemical Research (Synopses), no. 8, pp. 298-299, 1986.

[20] P. Sykes, A Guidebook to Mechanism in Organic Chemistry, Longman Scientific \& Technical, Harlow, UK, 6th edition, 1986.

[21] D. D. Perrin, W. L. F. Armarego, and D. R. Perrin, Purification of Laboratory Chemicals, Pergamon Press, New York, NY, USA, 2nd edition, 1980. 


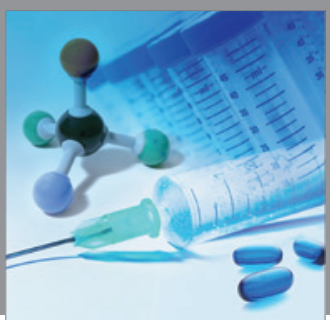

International Journal of

Medicinal Chemistry

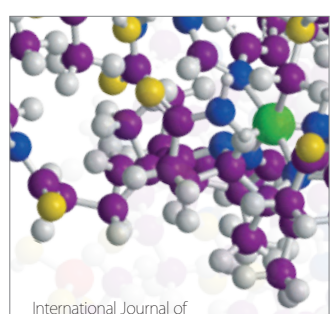

Carbohydrate Chemistry

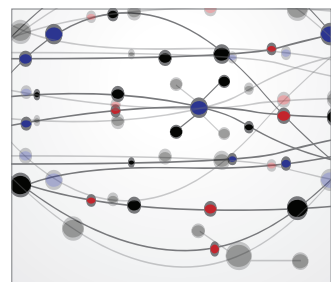

The Scientific World Journal
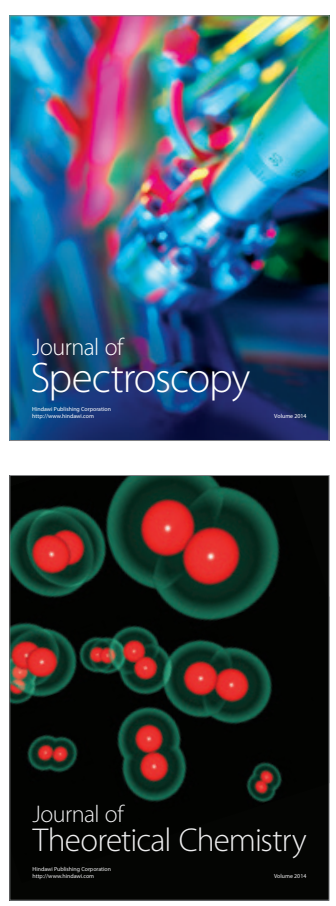
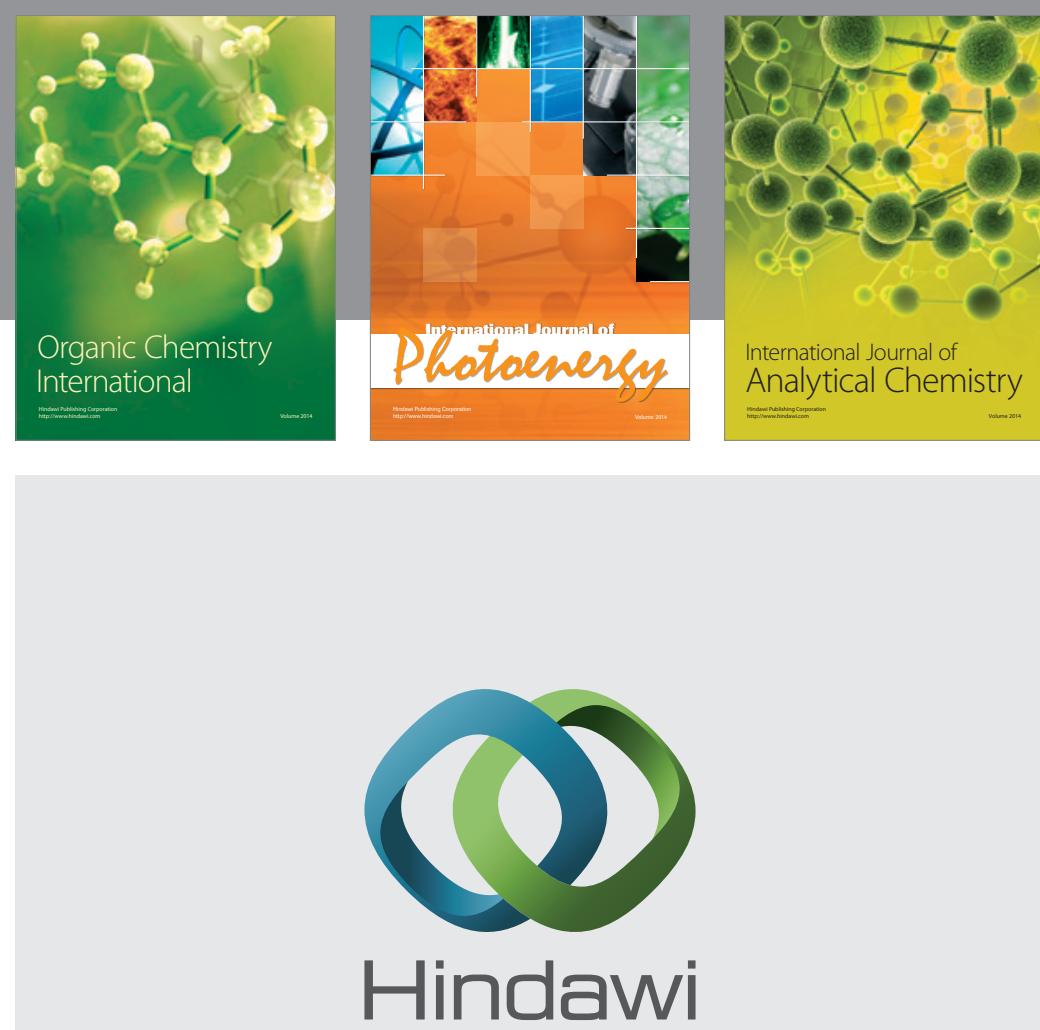

Submit your manuscripts at

http://www.hindawi.com
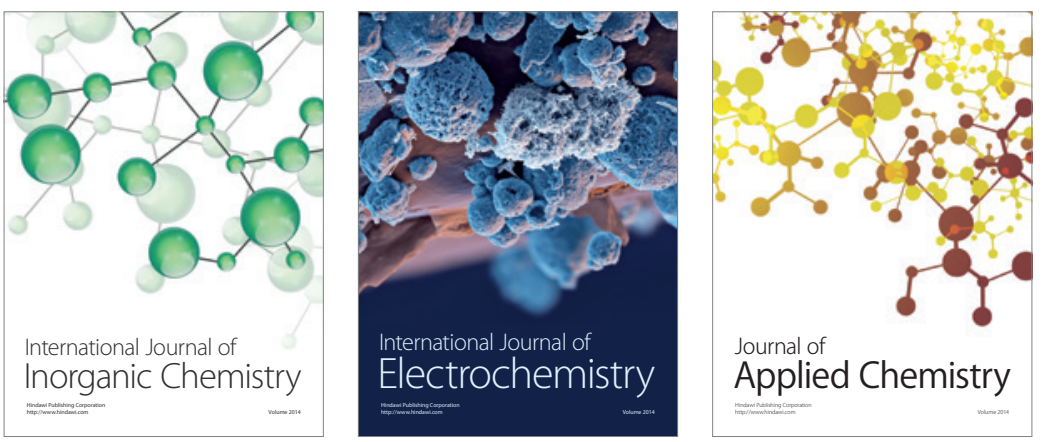

Journal of

Applied Chemistry
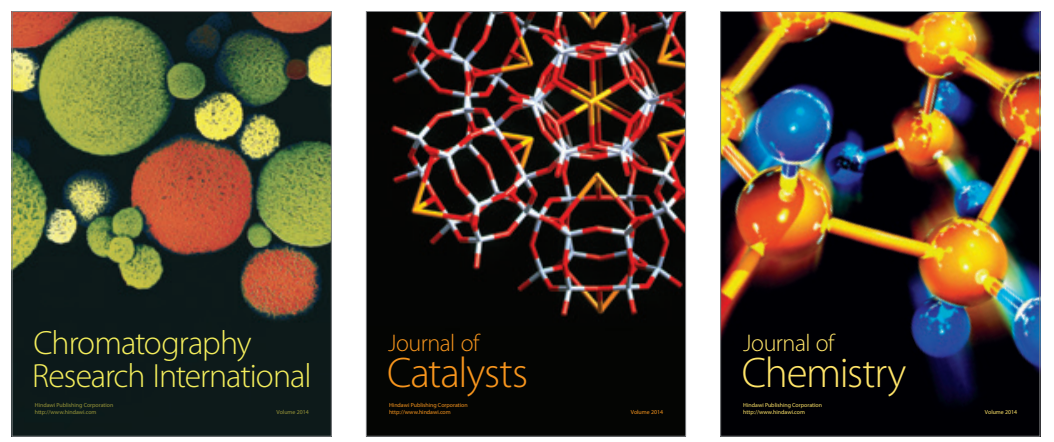
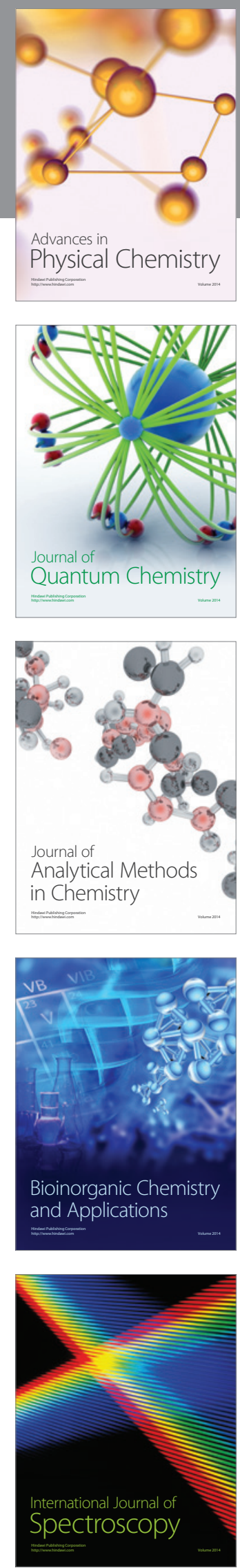